\title{
RANDOMIZED, DOUBLE BLIND CONTROLLED TRIAL TO COMPARE POST OPERATIVE ANALGESIC EFFICACY OF A SINGLE DOSE ADMINISTRATION OF CAUDAL LEVOBUPIVACAINE (0.25\%) VS ROPIVACAINE (0.25\%) IN INFRAUMBILICAL SURGERIES IN CHILDREN
}

Biswas $\mathrm{S}^{1}$, Mukherjee $\mathrm{G}^{2}$, Sarkar U. $\mathrm{K}^{3}$, Ghose T ${ }^{4}$, Das R ${ }^{5}$

\section{HOW TO CITE THIS ARTICLE:}

Biswas S, Mukherjee G, Sarkar UK, Ghose T, Das R. "Randomized, double blind controlled trial to compare post operative analgesic efficacy of a single dose administration of caudal Levo-Bupivacaine (0.25\%) VS Ropivacaine $(0.25 \%)$ in infraumbilical surgeries in children". Journal of Evolution of Medical and Dental Sciences 2013; Vol2, Issue 31, August 5; Page: 5740-5747.

BACKGROUND: - The rationale for replacing racemic bupivacaine with s-enantiomer levobupivacaine and ropivacaine is to provide a wider margin of safety. However of these two drugs which has better analgesic efficacy remains to be determined. In a randomized double blind control trial we have compared the post operative analgesic efficacy of levobupivacaine $0.25 \%$ and ropivacaine $0.25 \%$ in children undergoing infraumbilical surgeries. METHODS: - One hundred ASA I-II children less than 6 yrs scheduled for elective infraumbilical surgery were randomized to receive caudal block with levobupivacaine $0.25 \%$ or ropivacaine $0.25 \%$. The primary outcome of the study was to study the post operative analgesic efficacy of the two drugs. RESULTS: - There was no significant difference between the two study groups regarding the time to first rescue analgesia $(\mathrm{P}=0.06)$. Comparison of pain scores (CHEOPS) between the two study groups at various time points revealed no significant difference $(\mathrm{P}>0.05)$. CONCLUSION: - During infraumbilical surgeries in children ropivacaine and levobupivacaine provide similar and comparable post operative analgesic efficacy.

KEYWORD: - Anesthesia, paediatric; analgesic techniques, regional, caudal; anaesthetics local, levobupivacaine; anesthetics local, ropivacaine.

INTRODUCTION: - Pain is a complex, subjective, perceptual, phenomenon with a number of dimensions like intensity, quality, time course and impacts that are uniquely experienced by each individual. Children are most susceptible to pain because of their inability to express. Hence post operative pain control is important in paediatric population because poor control may result in increased morbidity and mortality [1]. Of the various multimodal approach in management of post operative pain neuraxial techniques are well tolerated by young children and are effective in suppressing stress response [2]. Caudal anesthesia is a useful adjunct during general anesthesia for providing post operative analgesia in children undergoing infra umbilical surgery. In children caudal anesthesia is performed in sedated or anesthetized condition hence detection of early symptoms of local anesthetic toxicity becomes extremely difficult. Although racemic bupivacaine $0.25 \%$ is the most commonly used local anesthetic via caudal route in paediatric population preliminary evidence suggests levobupivacaine and ropivacaine may be associated with less systemic toxicity $[4,5]$.

The rationale for replacing racemic bupivacaine with s-enantiomer levobupivacaine and ropivacaine is to provide wider margin of safety. Ropivacaine and levobupivacaine have shown to be effective and well tolerated by caudal route in children. However very few studies have compared efficacy of Levobupivacaine with Ropivacaine by caudal route in children. 


\section{ORIGINAL ARTICLE}

The aim of this randomized double blind control trial is to compare the post operative analgesic efficacy of ropivacaine $0.25 \%$ VS levobupivacaine $0.25 \%$ in children undergoing infra umbilical surgery.

MATERIAL AND METHODS: - After approval by the institutional ethics committee of Malda Medical College, informed written consent was obtained from the parents of 100 healthy children (ASA I or II). Children thus enlisted for the study were randomly allocated into two groups using a computer generated randomization chart. Patients were 1 to 6 yrs old and scheduled for elective infra umbilical surgery (Hypospadias correction, herniotomy, urethroplasty, anorectoplasty, recto vaginoplasty) with an anticipated duration of less than $90 \mathrm{~min}$.

Children were excluded in case of emergency surgery; known hypersensitivity to amide local anesthetics, a known history of active and severe renal, hepatic, respiratory or cardiac disease(including dysrhythmias or atrioventricular block) ; a history of seizure ; neurological or neuromuscular disorders; a history of chronic pain or analgesic drug use ; the presence of bloodclotting disorder, platelet count $<100000$ / cu mm; (platelet count was done in all cases as a part of routine haemogram which is a standard practice in our institution) blood dyscrasia; refusal or inability to receive a caudal epidural block; cutaneous infections or anatomical malformation at the puncture site ; and any other reason considered appropriate by the investigator.

Body weight of the patients was obtained on the day of surgery and baseline haemodynamic data noted. All children were fasted and received premedication with syrup diazepam orally, $0.3 \mathrm{mg} / \mathrm{kg}$ of body weight. Inhalation induction of general anesthesia was done with halothane (1\%$3 \%$ ) and maintained with $33 \%$ oxygen with $66 \%$ nitrous oxide. Intravenous (i.v.) access was secured with 22-24G after inhalational induction. Endotracheal intubation will be facilitated with atracurium besylate intravenously $0.5 \mathrm{mg} / \mathrm{kg}$ of body weight. Position of the endotracheal tube was confirmed by auscultation of the chest and capnographic wave form pattern. Tube was secured in that particular position. Patients were kept on intermittent positive pressure ventilation. Then caudal epidural block was performed by an expert anesthetist who will be unaware of the drug used, in left lateral decubitus position using an IV cannula (20-22G).

Patients were randomized to receive Levobupivacaine (0.25\%) (Group-L) [Levoanawin; Neon Laboratories] or Ropivacaine (0.25\%) (Group-R) [Ropin; Neon Laboratories]. A total dose of $0.5 \mathrm{ml} / \mathrm{kg}$ was used in each case. (All infraumbilical surgeries do not need the same amount of local anesthetic but the cases which we had selected were of the same duration and keeping the dose same we eliminated bias.)

The randomization sequence was computer generated and prepared in double-blind manner. Blinding was ensured by the following methods:

- The parents of the patients were unaware of which of the study drugs the patients received.

- The anesthesiologist administering the drug was unaware of which drug he/she was using.

- A different anesthesiologist who was not involved in the procedures of intra operative period was tasked with post operative monitoring and data collection

- The statistician who analyzed the results was unaware of the group allocation and the aim of the study. 


\section{ORIGINAL ARTICLE}

Each local anesthetic solution was prepared in a coded transparent $20 \mathrm{ml}$ syringe and labeled with the child's study number by the hospital central pharmacy. If the child was enrolled but did not undergo surgery, the child and the randomization assignment were replaced. In the case of emergency related or possibly related to the study or study drugs, the pharmacist was authorized to disclose the contents of the syringe to staff anesthetist. The study blinding was broken after the statistical analysis.

Intraoperative monitoring was done as per ASA minimum monitoring standards eg. ECG, NIBP, $\mathrm{EtCO}_{2}, \mathrm{SpO}_{2}$, Temp.

Surgical incision was allowed 5 mins after the caudal block. At the end of the surgery reversal from general anesthesia was done with injection neostigmine $0.05 \mathrm{mg} / \mathrm{kg}$ body weight and injection glycopyrrolate $0.01 \mathrm{mg} / \mathrm{kg}$ given intravenously. Patients were extubated once they are fully awake, moving all limbs and in presence of adequate cough reflex.(Post extubation the patients were kept in the post operative recovery before being shifted to ward) Patients were shifted to the ward when they were 1) alert and cooperative, 2) stable haemodynamics, 3) capable of maintaining airway, 4) capable of maintaining $\mathrm{SpO}_{2}$ more than 95\% in room air, 5) no signs of residual blockade, 6) CHEOPS(Table-1) score less than 4. If at that moment CHEOPS (TABLE-1) score was more than 6 then rescue analgesia was given in the form of Inj. Pentazocine $(0.6 \mathrm{mg} / \mathrm{kg}$ of body weight) intramuscularly. These patients were excluded from the study.

The primary and sole aim of this study is to compare the post operative analgesic efficacy of the two study drugs. During the post operative period an anesthetist not involved with the caudal block or anesthesia performed data collection regarding 1) time to administration of first rescue analgesia -------- the time between completion of caudal block and first post operative rescue

analgesia. 2) CHEOPS score at 30, 60, 90, 120, 150, 180 mins after extubation. All adverse effects from premedication until patient discharge were recorded. The mother of the child was allowed to stay with the patient in the post operative period and was explained to call the nurse for administration of rescue analgesic based on the following criteria-------

1) Inconsolable cry

2) Grimacing

3) Child complaining of pain

4) Position of torso----------restrained

5) Position of legs-------------restrained

6) Childs arm are restrained/ or vigorously grabbing the wound

If any three of the criteria are present the child will be given rescue analgesic in form of injection pentazocine $0.6 \mathrm{mg} / \mathrm{kg}$ intramuscular. (We agree that intramuscular pentazocine is not an analgesic of choice in paediatric population. Per rectal administration of paracetamol suppositories $20 \mathrm{mg} / \mathrm{kg}$ of body weight would have been a better alternative) the time of administration of rescue analgesic was noted and was considered the end point of data recording. Rescue analgesic was also given if the CHEOPS score was more than 6 as recorded by the observer. However haemodynamic monitoring and pain scoring was continued as a part of standard post anesthetic care. 


\section{ORIGINAL ARTICLE}

STATISTICAL ANALYSIS: Categorical variables were analyzed using Pearson's Chi square test. Normally distributed numerical variables were analyzed using unpaired " $t$ " test. Skewed numerical variables within the group were analyzed using Man-Whitney " $U$ " test. All tests were two tailed. Significance was defined as $\mathrm{P}<0.05$. All raw were entered into an excel spread sheet and analyzed using: 1> SPSS 16.0 [SPSS Inc ILLINOIS, USA, 2008]; 2> Statistical 6.0[stat soft Inc; Tulsa, Oklahama, USA, 2001]

RESULT: - Hundred children were enrolled, 50 in each group and all were analyzed on the basis of intention to treat. There were no significant difference in age, weight (2-tailed independent sample " $t$ " test) and sex distribution among the two study groups (Chi-square test).More patients receiving levobupivacaine underwent surgery for circumcision but there was no significant difference in the type of surgery between the two groups. (Chi-square test).

There was no significant difference between the two groups in there intraoperative haemodynamic parameters -----pulse rate and systolic and diastolic blood pressure. (Mann-Whitney U test).

There was no significant difference between the two groups in the duration of first rescue analgesic to be received as guided by CHEOPS score of 6 or more. The mean duration of administration of rescue analgesic in patient receiving levobupivacaine (group-L) was $1.7 \mathrm{~h}$ and $1.6 \mathrm{~h}$ in the ropivacaine (GROUP-R) group with a standard deviation of 36.435 in group-R and 26.589 in group-L. The median values between the two groups were not statistically significant, $\mathrm{P}=0.06$ (MannWhitney U test). (Table-2)

Comparison of the pain scores (CHEOPS) between the groups at various time points revealed no significant difference. The median values were not statistically different ( $P>0.05$ Mann- Whitney U test). (Table-3)

Five events of adverse effects were noted during the study period. All the events were mild to moderate in intensity and no serious adverse events were reported. Two patients in the both groups complained of nausea and vomiting. One patient in the levobupivacaine group complained of retention of urine. There was no incidence of any adverse neurological or cardiovascular events. Comparison between the two groups showed no significant statistically difference. ( $\mathrm{P}>0.05$ Pearson Chi-square Test).

DISCUSSION: - This study indicates that in children undergoing infraumbilical surgery levobupivacaine $0.25 \%$ is comparable to ropivacaine $0.25 \%$. Unlike a study conducted by Locatelli et al we kept the dose to be administered same for all the cases $(0.5 \mathrm{ml} / \mathrm{kg})$. By this we eliminated bias and at the same time prevented the risk of potential drug toxicity and higher level of block.

The decision to study ropivacaine and levobupivacaine as they have been proved to be equipotent on the basis of minimum local analgesic concentration (MLAC) method during active labour. Using very low concentrations ropivacaine appears $40 \%$ less potent than bupivacaine and equipotent with levobupivacaine. [7,8]

Very few studies have assessed the MLAC of local anesthetics in paediatric population undergoing caudal block. In order to achieve the same analgesic effect in children, a similar or lower concentration of ropivacaine is required in comparison with the same amount of levobupivacaine. This may imply that in children under light general anesthesia the local anesthetic concentrations 


\section{ORIGINAL ARTICLE}

used in clinical practice $(0.2 \%-0.25 \%)$, may reach the upper, flatter portion of the dose response curve, where potency differences are obscured.[8,9,10,11,12,13,14]

Levobupivacaine being a relatively new drug, clinical trials regarding its analgesic efficacy are few. In a randomized double -blind controlled study a caudal injection of Levobupivacaine $0.25 \%, 1 \mathrm{ml} / \mathrm{kg}$ was compared with ropivacaine $0.2 \%$ and bupivacaine $0.25 \%$. Levobupivacaine, Ropivacaine and bupivacaine presented comparable onset time and analgesia during and after surgery. [12] When compared with caudal ropivacaine $0.25 \%$, caudal levobupivacaine $0.25 \%$ provided similar anesthetic and analgesic block. ${ }^{[1,6]}$

We did not find any difference between the two study groups regarding the duration of analgesia. The duration of analgesia previously reported in various studies varies from 5 to $11 \mathrm{hrs}$, compared with a maximum analgesic time of 2 hrs in our study. [12,13,14, 15] (Past studies like those conducted by Taylor et showed the duration of levobupivacaine to be 7.3hrs. The drug used in this case was $2 \mathrm{mg} / \mathrm{kg}$ whereas we are using $0.5 \mathrm{ml} / \mathrm{kg}$ which is about $1.25 \mathrm{mg}$ in a $0.25 \%$ concentration drug. The big difference may be due to variability of dose of drugs use in various studies. However the study conducted by Locatelli et al have found the mean duration to be $2 \mathrm{hrs}$.)

Although local anesthetics are safe and effective, they may produce systemic toxic reactions affecting the heart and brain. Toxic reactions can occur from excessive doses of drug injected into appropriate tissue compartment by intravascular absorption or by inadvertent intravascular or intraosseous injection. ${ }^{[16]}$ In our study no such serious complications were noted excluding minor events of vomiting and retention of urine.

There is evidence that both levobupivacaine and ropivacaine are less cardiotoxic than bupivacaine. In a double blind crossover study in healthy male volunteers levobupivacaine administration resulted in significantly smaller reduction in stroke volume and ejection fraction compared with bupivacaine. [17] As levobupivacaine and ropivacaine produces similar central nervous and cardiovascular effects when infused i.v. at equal concentrations, doses and infusion rates, a large amount of both these drugs can be used as in caudal block without the risk of toxicity. We conducted this study to find out which of these two drugs provided better post operative analgesia in terms of duration.

In conclusion caudal levobupivacaine $0.25 \%$ provided reliable and similar analgesic efficacy when compared with ropivacaine $0.25 \%$ during infraumbilical surgeries in children.

ACKNOWLEDGEMENTS: The authors wish to thank the nursing staff and doctors of Dept. of Paediatric surgery, Malda Medical College and Hospital for their support during the study period, Dr S DeyRoy for protocol monitoring, Dr S Lahiri for protocol supervision. A special word of gratitude to Neon Laboratories for the logistic support rendered during the study.

\section{REFERENCES:}

1. Anand KJ, Hickey PR. Halothane morphine compared with high dose of sufentanil for anesthesia and post operative analgesia in neonatal cardiac surgery. N Eng J Med 1992 ;326:1

2. Na Kamura T, Takasiki M. Metabolic and endocrine response to surgery during caudal analgesia in children. Can J Anaesth 1999, 38:969 


\section{ORIGINAL ARTICLE}

3. Gunter JB. Benefit and risk of local anesthesia in infant and children. Paeditr Drugs 2002:4:649-72

4. Morrison SG, Dominguez JJ, Frascarolo P, Reiz S. A comparison of electrographic cardiotoxic effects of racemic bupivacaine, levobupivacaine, and ropivacaine in anesthetized swine. Anesth Anal 2000;90:1308-4

5. Mazoit JX, Dalens A, Bouaziz H, Edouard A. Comparative ventricular electrophysiological effect of racemic bupivacaine, levobupivacaine, and ropivacaine on the isolated rabbit heart. Anesthesiology 2000; 93: 784-92

6. Locatelli B, Ingelmo P, Sonzongi V. Randomized, double blind, phase III, controlled trial comparing levobupivacaine $0.25 \%$, ropivacaine $0.25 \%$, and bupivacaine $0.25 \%$ by caudal route in children. Br J Anesth 2005; 94(3): 366-71

7. Polley LS, Columb MO, Naughton NN, Wagner DS, Van de Ven CJ. Relative analgesic potencies of ropivacaine and bupivacaine for epidural analgesia in labor: implications for therapeutic indexes. Anesthesiology 1999; 90: 944-50

8. Polley LS, Columb MO, Naughton NN, Wagner DS, Van de Ven CJ, Goralsky KH. Relative analgesic potencies of levobupivacaine and ropivacaine for epidural analgesia in labor. Anesthesiology 2003; 99:1354-8

9. Mazoit JX, Dalens BJ. Ropivacaine in infants and children. Curr Opin Anaesthesiol 2003; 16: 305-7

10. Ivani G. Ropivacaine: is it time for children? Paediatr Anaesth 2002;12: 383-7

11. Astuto M, Disma N, Arena C. Levobupivacaine $0.25 \%$ compared with ropivacaine

$0.25 \%$ by caudal route in children. Eur J Anaesth 2003; 20: 826-30

12. Ivani G, De Negri P, Conio A, et al. Comparison of racemic bupivacaine, ropivacaine and levobupivacaine for pediatric caudal anesthesia: effects on postoperative analgesia and motor block. Reg Anesth and Pain Med 2002; 27:157-61

13. Khalil S, Campos C, Farag A, Vije H, Ritchey M, Chuang A. Caudal block in children. Ropivacaine compared with bupivacaine. Anesthesiology 1999; 91: 1279-84

14. Da Conceicao MJ, Coelho l, Khalil M. Ropivacaine $0.25 \%$ compared with bupivacaine $0.25 \%$ by caudal route. Paediatr Anaesth1999; 9: 229-33

15. Taylor R, Eyres R, Chalkiadis GA, Austin S. Efficacy and safety of caudal injection of levobupivacaine, $0.25 \%$, in children under 2 years of age undergoing inguinal hernia repair, circumcision orchidopexy. Paediatr Anaesth 2003; 13: 114-21

16. Berde CB. Toxicity of local anaesthetics in infants and children. J Pediatr 1993; 122: S14-S20.

17. Bardsley H, Gristwood R, Baker H, Watson N, Nimmo W. A comparison of the cardiovascular effects of levobupivacaine and rac-bupivacaine following intravenous administration to healthy volunteers. Br J Clin Pharmacol 1998; 46: 245-9. 


\section{TABLE-1}

\begin{tabular}{|c|c|c|c|}
\hline ITEM & BEHAVIOUR & SCORE & DEFINITION \\
\hline \multirow{4}{*}{ CRY } & No cry & 1 & Child is not crying \\
\hline & Moaning & 2 & Child is moaning, silent cry \\
\hline & Crying & 2 & Child is crying but the cry is gentle or whimpering \\
\hline & Scream & 3 & Child is in full lunged cry \\
\hline \multirow{3}{*}{ FACIAL } & Composed & 1 & Neutral facial expression \\
\hline & Grimace & 2 & Score only if definitive negative facial expression \\
\hline & Smiling & 0 & Score only if definitive negative facial expression \\
\hline \multirow{5}{*}{$\begin{array}{c}\text { CHILD } \\
\text { VERBAL }\end{array}$} & None & 1 & Child is not talking \\
\hline & Other comp. & 1 & Child complains but not of pain \\
\hline & Pain comp. & 2 & Child complains of pain \\
\hline & Both comp & 2 & Child complains of pain and other things \\
\hline & Positive & 0 & Child talks about other things without complaint \\
\hline \multirow{6}{*}{ TORSO } & Neutral & 1 & Body is at rest, torso is inactive \\
\hline & Shifting & 2 & Body is in motion in a shifting or serpentine fashion \\
\hline & Tense & 2 & Body is arched or rigid \\
\hline & Shivering & 2 & Body is shuddering or shaking involuntarily \\
\hline & Upright & 2 & Child is vertical or in upright position \\
\hline & Restrained & 2 & Body is restrained \\
\hline \multirow{5}{*}{ TOUCH } & Not touching & 1 & Child is not touching or grabbing at wound \\
\hline & Reach & 2 & Child is reaching for but not touching wound \\
\hline & Touch & 2 & Child is gently touching wound or wound area \\
\hline & Grab & 2 & Child is grabbing vigorously at wound \\
\hline & Restrained & 2 & Child" \\
\hline ITEM & BEHAVIOUR & SCORE & DEFINITION \\
\hline \multirow{5}{*}{ LEGS } & Neutral & 1 & Legs may be in any position but are relaxed \\
\hline & Kicking & 2 & Definitive uneasy or restless movements in legs \\
\hline & Tensed & 2 & Legs tensed and/or pulled up tightly \\
\hline & Standing & 2 & Standing, crouching or kneeling \\
\hline & Restrained & 2 & Child's legs are being held down \\
\hline
\end{tabular}

Table-1: CHILDREN"S HOSPITAL OF EASTERN ONTARIO PAIN SCALE (CHEOPS)

TABLE-2

Table 2: Comparison of TIME TO RESCUE ANALGESIC (in minutes) between groups.

\begin{tabular}{|c|c|c|c|c|c|c|}
\hline Group & $\mathbf{n}$ & Mean & Median & Min & Max & Std. Dev \\
\hline $\mathrm{R}$ & 50 & 94.18 & 96.00 & 40 & 120 & 36.435 \\
\hline $\mathrm{L}$ & 50 & 100.15 & 102.00 & 60 & 150 & 26.589 \\
\hline
\end{tabular}


Table 2: summarizes the descriptive statistics of time to rescue analgesic in the two groups. The median values were not statistically significant. ( $p>0.05$ Mann-Whitney $U$ test). TABLE-3: Comparison of PAIN SCORES (C.H.E.O.P.S.) between groups at various time points.

\begin{tabular}{|c|c|c|c|c|c|c|c|}
\hline & Group & $\mathbf{n}$ & Mean & Median & Min & Max & Std. Dev \\
\hline \multirow{3}{*}{ 30min } & $\mathrm{R}$ & 50 & 3.00 & 3.00 & 3 & 3 & 0.000 \\
\cline { 2 - 8 } & $\mathrm{L}$ & 50 & 3.00 & 3.00 & 3 & 3 & 0.000 \\
\hline \multirow{3}{*}{$60 \mathrm{~min}$} & $\mathrm{R}$ & 50 & 3.56 & 3.00 & 3 & 6 & 0.961 \\
\cline { 2 - 8 } & $\mathrm{L}$ & 50 & 3.16 & 3.00 & 3 & 6 & 0.624 \\
\hline \multirow{2}{*}{ 90mins } & $\mathrm{R}$ & 50 & 4.22 & 4.00 & 3 & 8 & 1.043 \\
\cline { 2 - 8 } & $\mathrm{L}$ & 50 & 4.08 & 4.00 & 3 & 8 & 1.018 \\
\hline \multirow{2}{*}{ 120min } & $\mathrm{R}$ & 50 & 5.27 & 5.00 & 4 & 9 & 1.549 \\
\cline { 2 - 8 } & $\mathrm{L}$ & 50 & 6.00 & 6.00 & 4 & 9 & 1.679 \\
\hline \multirow{2}{*}{ 150mins } & $\mathrm{R}$ & 50 & 7.00 & 7.50 & 5 & 9 & 1.506 \\
\cline { 2 - 8 } & $\mathrm{L}$ & 50 & 6.91 & 7.00 & 5 & 8 & 1.300 \\
\hline \multirow{2}{*}{ 180mins } & $\mathrm{R}$ & 50 & 8.20 & 8.00 & 7 & 9 & 0.837 \\
\cline { 2 - 8 } & $\mathrm{L}$ & 50 & 8.67 & 9.00 & 8 & 9 & 0.577 \\
\hline
\end{tabular}

Table 3: Summarizes the pain scores between Group $R$ and Group B at various time points. The median values were not statistically different ( $p>0.05$ Mann-Whitney $U$ test)

\section{AUTHORS:}
1. Biswas $\mathrm{S}$.
2. Mukherjee G.
3. Sarkar U K.
4. Ghose T.
5. Das R.

\section{PARTICULARS OF CONTRIBUTORS:}

1. Clinical Tutor, Dept. of Anesthesiology, MMCH.

2. Professor and HOD, Dept. of Anesthesiology, MMCH.

3. Professor, Dept. of Anesthesiology, MMCH.

4. Assistant Professor, Dept. of Anesthesiology, IPGMER, Kolkata.

5. Clinical Tutor, Dept. of Gynae \& Obst., $\mathrm{MMCH}$.

\section{NAME ADRRESS EMAIL ID OF THE CORRESPONDING AUTHOR: \\ Dr. Saumya Biswas, \\ 815/C, Block - A, \\ Laketown, Kolkata - 89, \\ West Bengal. \\ Email - saumya.biswas@gmail.com}

Date of Submission: 14/07/2013.

Date of Peer Review: 15/07/2013.

Date of Acceptance: 29/07/2013.

Date of Publishing: 30/07/2013 